\title{
BLOQUEIO INTERMITENTE DA BR-174 PELO POVO INDÍGENA WAIMIRI-ATROARI: Necessidade de Consulta Prévia em Caso de Intervenção Estatal Sobre o Seu Território
}

\author{
http://dx.doi.org/10.21527/2176-6622.2020.53.91-105
}

Recebido em: 11/11/2019

Aceito em: 20/1/2020

Daniel Reis e Silva

Graduado em Direito pela Universidade Federal do Amazonas. Pós-graduado lato sensu em Direito Processual Civil pela Universidade Federal do Amazonas e pós-graduado lato sensu em Direito Público pela Faculdade Damásio. Assistente Judiciário no Tribunal de Justiça do Estado do Amazonas. http://lattes. cnpq.br/0071719622336036. https://orcid.org/0000-0002-1015-296X. danielreisesilva@gmail.com

\section{Alex Penha do Amaral}

Bacharel em Direito pela Universidade Federal do Amazonas. Especialista em Direito Tributário pela Universidade Estácio de Sá. Especialista em Direito Processual Civil pela Universidade Federal do Amazonas. Servidor público efetivo ocupante do cargo de assistente técnico na Secretaria de Estado de Produção Rural no Amazonas com atuação junto a Comissão de Tomada de Contas Especial, a Comissão de Inexecução de Contratual, a Comissão de Processo Administrativo Disciplinar e Sindicância e a Comissão de Levantamento e Avaliação Patrimonial. Assistente-adjunto na 3a Vara Federal da Seção Judiciária do Amazonas com atuação na área cível. Diretor substituto do Centro Judiciário de Conciliação da Justiça Federal do Amazonas - Seção Judiciária do Amazonas. http://lattes.cnpq.br/2286678875841527. https://orcid.org/0000-00016993-2517.alexpamaral@outlook.com

Raimundo Pereira Pontes Filho

Doutor em Sociedade e Cultura na Amazônia pela Universidade Federal do Amazonas - Ufam. Mestre em Direito Ambiental pela Universidade do Estado do Amazonas-UEA. Bacharel em Direito pela Universidade Federal do Amazonas. Bacharel e Licenciado em Ciências Sociais pela Universidade Federal do Amazonas. Professor, exerce a docência desde 1996. É pesquisador de história da Amazônia e direitos socioculturais na região com livros publicados sobre esses temas, dentre os quais: Logospirataria na Amazônia, História do Amazonas, vício e criminalidade, terceiro ciclo. Professor da Universidade Federal do Amazonas. Docente do Programa de Mestrado em Segurança Pública da Universidade do Estado do Amazonas. Servidor público do Estado do Amazonas. http:// lattes.cnpq.br/5195892868453324.https://orcid.org/0000-0001-9765-2053.pontesfilho555@yahoo.com.br

\section{RESUMO}

Nos últimos 40 anos, o povo indígena Waimiri-Atroari tem bloqueado diariamente, durante a noite, o acesso ao trecho da estrada BR-174 que corta o seu território, entre os Estados do Amazonas e Roraima, enquanto o Poder Público, reforçado pelo discurso em voga no governo federal, tenta encontrar meios de abolir a prática. Por meio de um estudo dedutivo, a presente pesquisa partirá de uma contextualização histórica dos impactos da construção da estrada sobre o povo indígena, pautada numa política colonialista de extermínio, para então descrever a problemática como persiste no presente. Posteriormente, será abordado o plexo de direitos constitucionais garantidos aos povos indígenas, tais como a posse permanente e o usufruto exclusivo para o desenvolvimento próprio e proteção das terras tradicionalmente ocupadas. Em seguida, ressaltar-se-á a possibilidade de intervenção do Estado sobre o território indígena, como medida de desenvolvimento econômico, desde que observado o conjunto de direitos fundamentais e assegurada a consulta prévia, livre e informada do povo indígena a ser afetado, objeto do tópico final. Por fim, o trabalho denota que tratamentos inferiorizantes e estigmatizantes dos povos indígenas pelo Poder Público não mais são tolerados pelo ordenamento vigente, que abandonou qualquer viés colonialista. A intervenção estatal que venha a limitar o direito territorial indígena deve observar a consulta prévia e garantir efetivo diálogo intercultural, para que o povo afetado assuma posição de protagonismo no processo decisório quanto à questão do bloqueio da estrada.

Palavras-chave: Constitucional. Indígena. Waimiri-Atroari. Território. Consulta. 
BR-174 INTERMITTENT BLOCKAGE BY WAIMIRI-ATROARI INDIGENOUS PEOPLE: NEED FOR PRIOR CONSULTATION IN CASE OF STATE INTERVENTION ON THEIR TERRITORY

\section{ABSTRACT}

Over the past forty years, the Waimiri-Atroari indigenous people have been blocking daily access at night to the stretch of highway BR-174 that cuts through their territory, between the states of Amazonas and Roraima, while the government, reinforced by the current speech in the federal government, tries to find ways to abolish the practice. Through deductive study, this research will start from a historical contextualization of the impacts of the construction of the road on the indigenous people, based on a colonialist policy of extermination, to then describe the problem as it persists in the present. Subsequently, the study addresses the plexus of constitutional rights guaranteed to indigenous peoples, such as permanent tenure and exclusive enjoyment for their own development and protection of traditionally occupied lands. Then, it approaches the possibility of State intervention on indigenous territory, as a measure of economic development, provided that the set of fundamental rights is observed, including prior, free and informed consultation of the indigenous people to be affected. Finally, the work shows that lowering and stigmatizing treatment of indigenous peoples by the Government is no longer tolerated by the current law, which abandoned any colonialist bias. State intervention that may limit indigenous territorial law must observe prior consultation and ensure effective intercultural dialogue, so that the affected people can take a leading role in the decision-making process regarding the issue of road blockage.

Keywords: Constitutional. Indigenous. Waimiri-Atroari. Territory. Consultation.

\section{SUMÁRIO}

1 Introdução. 2 A trajetória histórica do povo indígena Waimiri-Atroari e sua relação com a construção e o bloqueio da BR-174. 2.1 A construção da BR-174: política de desenvolvimento na época da ditadura. 2.20 conflito atual: bloqueio da BR-174 por parte do povo Waimiri-Atroari. $3 \mathrm{Um}$ recorte do panorama nacional e internacional de direitos territoriais indígenas: autodeterminação e posse permanente sobre as terras tradicionalmente ocupadas. 3.10 paradigma assimilacionista e sua ruptura com a Constituição de 1988. 3.2 O delineamento constitucional do direito territorial no artigo 231 da CF/88: considerações sobre o direito originário, a propriedade da União e o usufruto exclusivo. 3.30 procedimento de demarcação de terras indígenas. 4 A consulta prévia como instrumento de reconhecimento da autodeterminação dos povos indígenas. 4.1 Intervenção estatal e o direito à consulta prévia, livre e informada dos povos indígenas. 4.2 Considerações sobre o novo constitucionalismo latino-americano e a transição para um paradigma jurídico pluralista. $4.3 \mathrm{~A}$ consulta prévia como instrumento de reconhecimento. 4.4 A consulta prévia como instrumento de autodeterminação. 5 Conclusão. 6 Referências.

\section{INTRODUÇÃO}

A construção da estrada BR-174, que liga os municípios de Manaus e Boa Vista, seguiu uma trajetória tortuosa de graves conflitos envolvendo interesses político-econômicos e o povo indígena Waimiri-Atroari, entre os anos de 1968 e 1977. Como resultado da resistência às agressivas políticas assimilacionistas e à tutela estatal durante esse período, os Kinja - como autodenomina-se esse povo, que habita região na fronteira dos estados do Amazonas e Roraima - tiveram sua população drasticamente reduzida e seus territórios ocupados por atuação governamental, que via na estrada um fato irreversível, necessário ao desenvolvimento do país e à segurança nacional. A história da estrada BR-174 é marcada, portanto, por políticas de extermínio, e o avanço desmedido sobre o território indígena tradicionalmente ocupado, causou feridas permanentes que o povo carregará ao longo de sua existência.

Nos anos que se seguiram à construção da estrada, os Waimiri-Atroari adotaram a prática - que persiste até hoje - de bloquear o fluxo de veículos na estrada entre as 18 e as 6 horas, todos os dias, como medida de proteção territorial e preservação da fauna silvestre. Diante disso, representantes de setores produtivos e do próprio governo, imputando a tal prática o estigma do "atraso" do desenvolvimento econômico da região, têm se articulado para encontrar meios de aboli-la. Em 28 de março de 2019, a Assembleia Legislativa de Roraima promoveu audiência pública envolvendo os representantes dos setores sociais interessados, em que se ressaltou o alinhamento de objetivos desenvolvimentistas das esferas estadual e federal do governo com as perspectivas dos setores produtivos, unidos em prol da livre-locomoção na estrada, após 40 anos de bloqueio intermitente por parte do povo indígena.

A problemática ora analisada, portanto, reside nesse conflito atual e nos direitos reconhecidos pelo ordenamento tanto ao governo, de intervir em território indígena, quanto aos povos indígenas, de protegerem seu território e de serem consultados previamente a respeito de qualquer medida do Poder Público que possa vir a afetá-los. O trabalho iniciar-se-á com breve contextualização histórica, uma exposição da trajetória do povo indígena Waimiri-Atroari e dos impactos da construção da BR-174 sobre sua existência - na medida em que a história, imprescindível à discussão sobre a cultura e direito indígena no Brasil, exerce influência 
direta sobre os direitos reconhecidos e os conflitos atuais, e permite uma melhor compreensão da resistência indígena aos avanços da sociedade hegemônica -, chegando, então, ao caso concreto presente: a problemática do bloqueio temporário da estrada por parte dos indígenas e a possível intervenção estatal para impedir a prática.

Em seguida, proceder-se-á, sem pretensão de esgotar o assunto, a um recorte dos direitos territoriais indígenas, conforme delineados pela atual Constituição, direitos esses que fundamentam a prática de bloqueio temporário do fluxo de veículos na estrada. Por outro lado, ressaltar-se-ão a possibilidade de intervenção estatal em território indígena, inclusive a fundada em promoção de desenvolvimento econômico, o limite imposto pelo ordenamento jurídico a essa intervenção - a que se dedicará o tópico final - e o direito à consulta prévia, livre e informada dos povos indígenas em caso de medidas governamentais que venham a afetá-los, consoante previsão na Convenção n. 169 da Organização Internacional do Trabalho, incorporada ao ordenamento pátrio.

Ao fim, restará claro que o conjunto de direitos constitucionais indígenas vigentes, embora representem uma ruptura com os padrões colonialistas de comportamento do governo em relação aos índios (como demonstrado no primeiro tópico), e fundamentais à preservação da identidade e cultura indígena, não são absolutos. Se não pode ser impedida, de modo nenhum, a intervenção estatal como medida de garantia ao desenvolvimento econômico (ou outros propósitos de interesse da sociedade hegemônica), deve-se garantir a preservação do direito à consulta prévia, livre e informada do povo indígena Waimiri-Atroari, não como mera formalidade, mas como instrumento de efetivo diálogo intercultural, que propicie a ambas as partes a capacidade de influenciar o processo decisório.

O Poder Público tem se articulado durante o ano de 2019 para agilizar esse processo decisório quanto ao fim do bloqueio da estrada, sob incentivo de discursos colonialistas oriundos do governo federal. A escolha do tema justifica-se em sua atualidade e na necessidade de trazer à lume a visão colonialista e estigmatizante com que as diferentes camadas da sociedade enxergam os povos indígenas, para servir ao propósito de substituí-la por uma visão descolonial e intercultural, pautada no texto constitucional vigente e na garantia do direito à consulta prévia.

O método de pesquisa adotado será o dedutivo. Chegar-se-á à proposta de solução do caso concreto analisado a partir de um cotejo geral dos direitos vigentes. O procedimento de pesquisa será a análise bibliográfica de obras jurídicas e históricas nacionais sobre o tema indígena, bem como de documentos processuais em ações civis públicas que tratam da questão e, especificamente, do povo indígena Waimiri-Atroari. O delinear do arcabouço jurídico, aplicável ao caso concreto, levará à solução jurídica razoável para a problemática, sem violação do núcleo essencial de direitos fundamentais.

\section{A TRAJETÓRIA HISTÓRICA DO POVO INDÍGENA WAIMIRI-ATROARI E SUA RELAÇÃO COM A CONSTRUÇÃO E O BLOQUEIO DA BR-174}

\subsection{A construção da BR-174: política de desenvolvimento na época da ditadura}

A memória, diferentemente da história, é conceito em permanente evolução, carregada por grupos vivos no presente. Enquanto a história reconstrói, de forma problemática e incompleta, o que não existe mais, a memória sofre deformações sucessivas, é vulnerável a usos e manipulações e aberta à dialética da lembrança e do esquecimento. Como elo vivido no presente, a memória pertence a determinado grupo e o une.

Na medida em que é construída pela nação uma história oficial de si mesma, as memórias do grupo são criadas, e os símbolos e valores considerados marcantes são cultivados e enaltecidos. Em contrapartida, fatos e personalidades a quem não se atribui grandiosidade são inferiorizados: o conjunto de narrativas oficiais da história elabora, então, esquecimentos (ARAUJO JR., 2018, p. 121-122). 
Desde a colonização, a inferiorização tem sido uma forma permanente de tratamento dos povos indígenas. Na República, como expõe João Pacheco de Oliveira (2016 apud ARAUJO JR., 2018, p. 124), a compreensão da trajetória desses povos e os regimes de memória construídos a partir da história oficial, retrataram-nos como primitivos, que precisavam ser tutelados para se integrar à civilização. Caberia ao índio não interferir no projeto nacional, fundado em ideais de desenvolvimento e progresso. ${ }^{1}$

As abordagens coloniais de extermínio não foram, contudo, bem-sucedidas na tentativa de transformar os povos indígenas em mera lembrança na construção da história oficial. Os grupos resistentes organizaram-se em territórios e reivindicaram direitos, autoafirmando-se etnicamente (ARAUJO JR., 2018, p. 126).

No caso do povo Waimiri-Atroari, de que trata o presente artigo, a intervenção estatal causou danos de enorme monta, notadamente durante o período de construção da BR-174, entre 1968 e 1977. A narrativa que se propagou, em relação a esse episódio da história, colocou o povo Waimiri-Atroari como empecilho ao progresso pretendido pelo governo da ditadura militar. A construção da referida rodovia compunha o projeto de integração territorial daquela época, cujo objetivo era promover a ocupação das terras pelo interior do país, em prol, sobretudo, da segurança nacional.

O povo Waimiri-Atroari tem uma história marcada por violações dos seus modos de vida, do seu espaço territorial tradicionalmente ocupado e do exercício de sua identidade. Trata-se de um povo situado na fronteira dos Estados do Amazonas e de Roraima, que se autodenomina Kinja e fala a língua Karib. A denominação Waimiri-Atroari, dada pelos brancos, corresponde à região ocupada pelos autóctones: Waimiri como habitantes do sul e Atroaris como residentes mais ao norte. Sucede que tal distinção não persiste entre os indígenas, tendo em vista que a localização geográfica é o único aspecto distintivo - ação civil pública no 100160506.2017.4.01.3200, 2017, p. 6, num. 2518053 (BRASIL, 2017).

Entre todas as invasões sofridas historicamente pelo povo Waimiri-Atroari, a decorrente do projeto de construção da BR-174 tornou-se a mais emblemática, pois provocou um grande genocídio desse povo, implicando redução populacional alarmante, conforme constata-se na ação civil pública no 100160506.2017.4.01.3200 (BRASIL, 2017), proposta pelo Ministério Público Federal - MPF -, visando à reparação dos danos provocados pela empreitada estatal. A composição da ação decorre dos estudos realizados por um grupo de trabalho destinado a investigar os povos indígenas no período do regime militar.

Segundo os registros feitos pelo MPF, a construção da BR-174 produziu muitos impactos negativos ao povo Waimiri-Atroari, por ter sido projetada sob a visão integracionista adotada pelo Estado brasileiro à época, que acreditava na integração gradual dos povos indígenas à sociedade ocidental hegemônica (sociedade dita "civilizada"), reconhecendo, pois, sua inferiorização em relação a esta.

Com base nesse pensamento, a estratégia política para lidar com os povos indígenas diante dos empreendimentos estatais, estava assentada nos processos de "pacificação" e de extermínio. O primeiro era empregado para buscar a adesão dos povos tradicionais aos projetos estatais por meio de seu convencimento, a fim de evitar a adoção de meios coercitivos e o surgimento de conflitos. Já o segundo mantinha-se de forma velada pelo Estado, não sendo adotado oficialmente. Este último correspondia à faceta mais direta das violências praticadas contra os indígenas, apresentado como mecanismo subsidiário.

No caso do povo Waimiri-Atroari, a ditadura civil-militar recorreu as duas estratégias em virtude da falta de êxito nos trabalhos da "pacificação" e, em 1974 e 1976, foram empregadas demonstrações de força militar pelo 6으 Batalhão de Engenharia e Construção com o objetivo de subjugar os Waimiri-Atroari por oferecerem resistência aos interesses econômicos do país, pretendidos com a abertura de fronteiras, ocupação e integração do espaço territorial, que estavam ligados à construção da BR-174.

\footnotetext{
O autor Roberto Cardoso de Oliveira, citado por Julio Araujo, esquematiza o tratamento dado aos povos indígenas e o categoriza em quatro tipos de mentalidade: estatística, romântica, burocrática e empresarial: "A mentalidade estatística pergunta: Por que nos preocupamos com alguns milhares de índios, se o grande problema é o destino de um país com milhões de habitantes? A mentalidade romântica carrega a visão estereotipada e ingênua do bom selvagem, que desumaniza o indígena e serve para tratar como imperdoáveis as "faltas" que os autóctones cometem quando não atendem ao modelo preestabelecido. A mentalidade burocrática é aquela dos agentes públicos e funcionários, que, salvo aqueles imbuídos de espírito humanitário, se mostram indiferentes e pouco sensíveis à temática, reforçando a ideia dos indígenas como "questão" ou "problema" a serem resolvidos. A mentalidade empresarial prega a transformação de áreas indígenas em empresas, dedicadas à produção e ao lucro, como se o indígena somente pudesse ser considerado um civilizado se adentrasse o mundo do trabalho dos brancos (ARAUJO JR., 2018, p. 124).
} 
Nesse diapasão, verifica-se que a construção da BR-174, inaugurada em 6 de abril de 1977, infligiu ao povo Waimiri-Atroari a violação de diversos direitos, chegando a ameaçar sua próprias existência. Consoante os dados apurados pelo MPF, contabilizaram-se 323 indígenas vivos após a construção da estrada (19771983), tendo a Comissão Nacional da Verdade, instituída para os fatos referentes ao período entre 1946 e 1985, concluído pela morte de 2.650 indígenas Waimiri-Atroari durante a construção da rodovia.

O exemplo ora tratado de aplicação da proposta integracionista deixa evidente a invisibilidade dos indígenas perante a sociedade nacional, sendo vistos como obstáculos ao desenvolvimento nacional. O contato com os indígenas Waimiri-Atroari revela a ausência de preocupação do Estado brasileiro, à época do regime militar, com o sistema de vida dos índios, buscando-se tão somente a defesa dos interesses nacionais em detrimento até mesmo dos direitos fundamentais desse povo.

Não obstante o deslocamento forçado e a desterritorialização, provocados pela construção da rodovia, a demarcação administrativa da terra indígena Waimiri-Atroari foi homologada por meio do Decreto n. 97.837, de 16 de junho de 1989 (BRASIL, 1989). No parágrafo único do seu artigo 2º, entretanto, o Decreto excluiu da área indígena a faixa de domínio da BR-174, apesar de tratar-se de território tradicional dos Waimiri-Atroari.

Figura 1 - Área demarcada da terra indígena Waimiri-Atroari

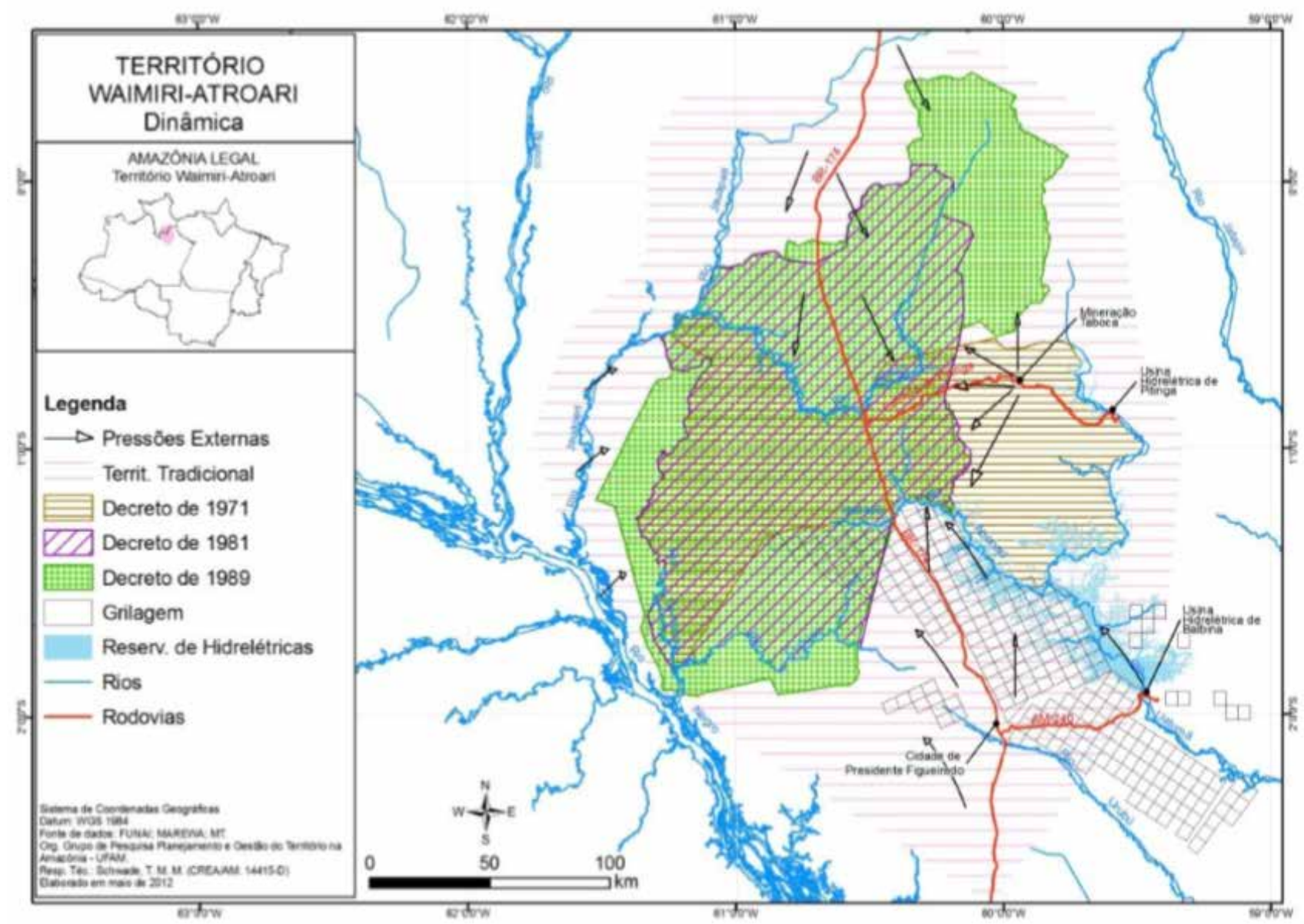

Fonte: BRASIL, 2017.

\subsection{O conflito atual: bloqueio da BR-174 por parte do povo Waimiri-Atroari}

Feitas considerações sobre o processo de construção da BR-174, mostra-se oportuno traçar os contornos atuais do conflito estudado. 
No dia 28 de março de 2019, o Poder Legislativo Estadual realizou, em Boa Vista/RR, audiência pública com autoridades ligadas ao governo, sindicato dos trabalhadores de transporte, produtores, associações e alguns representantes indígenas. $O$ objetivo era discutir a respeito do bloqueio da estrada BR-174, realizado diariamente desde $1997^{2}$ pelos indígenas e funcionários do Programa Waimiri-Atroari no período das 18 horas até as 6 horas.

Inaugurada a estrada, persistiram nos últimos 40 anos conflitos envolvendo a obra e a terra indígena Waimiri-Atroari. Em exercício de seus direitos territoriais originários, reconhecidos a partir da ocupação tradicional da área, os indígenas interrompem o fluxo no trecho inserido na terra indígena, que se estende do posto fiscal de Jundiá/RR a Abonari/AM, com aproximadamente $125 \mathrm{~km}$ de extensão. Durante o período, somente ônibus interestaduais, ambulâncias e caminhões que carregam cargas perecíveis podem passar, como destaca Moura (2017). A medida proporciona a preservação do território e da fauna silvestre, previne conflitos noturnos e serve para reforçar a posse permanente e o usufruto exclusivo indígena, garantidos pelo artigo 231 da Constituição Federal (BRASIL, 1988) a partir de uma temporária restrição do direito de locomoção na estrada.

Diante do intento interventivo do Estado sobre tal território, no sentido de retirar em definitivo o bloqueio do fluxo noturno na estrada - objetivo esse renovado pelos recentes discursos sobre política indigenista vindos da esfera federal do governo e reforçado no âmbito da recente audiência pública realizada em Boa Vista/RR ${ }^{3}$-, sobressai a importância de discussão a respeito do direito territorial indígena garantido em sede constitucional e internacional. A ordem posta já não permite a reprodução de perspectivas inferiorizantes e colonialistas, a imposição do estigma do "atraso" à cultura indígena para fins de hierarquização ou a livre-intervenção em seu território a pretexto de privilegiar determinado conceito individualista e hegemônico de desenvolvimento econômico.

O direito vigente proporciona ao povo indígena meios de preservar sua ocupação tradicional, a biodiversidade e os seus recursos naturais e culturais, e de decidir os rumos do seu próprio desenvolvimento no âmbito do seu território. Nesse sentido, a possível intervenção estatal sobre esse território deve observar o conjunto de normas e interpretações constitucionais, abertas ao diálogo intercultural, e, conforme destacar-se-á em tópico próprio neste trabalho, o direito à consulta prévia, livre e informada dos povos indígenas caso se cogite a adoção de qualquer medida que possa vir a afetá-los, direito esse originado em tratado internacional de direitos humanos ratificado pelo Brasil e incorporado ao nosso ordenamento - que não se resume à participação indígena em audiências públicas realizadas pelo Poder Público.

\section{UM RECORTE DO PANORAMA NACIONAL E INTERNACIONAL DE DIREITOS TERRITORIAIS INDÍGENAS: AUTODETERMINAÇÃO E POSSE PERMANENTE SOBRE AS TERRAS TRADICIONALMENTE OCUPADAS}

\subsection{0 paradigma assimilacionista e sua ruptura com a Constituição de 1988}

A terra, como espaço de vida e liberdade de um grupo humano, tem sido a reivindicação primordial dos povos indígenas brasileiros e latino-americanos. Para esses agrupamentos, a territorialidade, etnicamente construída, funciona como fator de identificação, defesa e força (ALMEIDA, 2008, p. 29), e tem papel principal na própria existência e sobrevivência dos povos e de suas referências culturais; o território, o ecossistema nele presente e o domínio e saber do povo sobre esse território, compõem sua identidade (SOUZA FILHO, 2006, p.

\footnotetext{
2 Moura explica que "durante a construção da BR-174 e após o término da rodovia, o '60 BEC passou a monitorar o trecho da BR-174 incidente na reserva Waimiri Atroari' e, em virtude dos conflitos ali travados, barrava o fluxo de automóveis no período noturno" (2017, p. 21), o que perdurou até 1997, quando os próprios indígenas assumiram o bloqueio.

3 Na audiência, representantes dos setores produtivos e sindicalistas apontaram a medida de bloqueio como um dos maiores entraves para o desenvolvimento da economia do Estado por inviabilizar a produção. Representantes do Poder Público estadual e municipal reafirmaram o interesse político de liberação da passagem, apontando a necessidade de diálogo com a comunidade afetada. Ressaltou-se, na oportunidade, a ausência de norma que autorize o fechamento da estrada e a necessidade de desenvolvimento pacífico do Estado. Foi levantada, ainda, a necessidade de atuação do governo federal no sentido de tratar o tema de forma plena e consciente, em consideração ao histórico de prejuízos impostos aos povos que sempre viveram na Amazônia. Trechos de entrevistas com os representantes presentes podem ser visualizados nos seguintes endereços, disponibilizados pela Assembleia Legislativa de Roraima: https://www.youtube.com/watch?v=aQHov_nqD0c; https://www.youtube.com/watch?v=RGatoT48Xgc.
} 
119-120). Sob tal prisma, mostra-se nítida a discrepância entre a concepção de território oriunda dos povos indígenas e a da sociedade hegemônica, esta intimamente vinculada à soberania de um Estado nacional construído a partir dos anseios da sociedade burguesa de matriz europeia, motivo pelo qual persiste a resistência a considerar a área ocupada por esses povos como "territórios" (SOUZA FILHO, 2006, p. 121).

No contexto brasileiro, antes da Constituição de 1988, prevaleceu, na atuação do Poder Público e nas normas atinentes aos direitos territoriais indígenas, um forte viés assimilacionista: o interesse dos povos indígenas deveria subordinar-se a interesses nacionais e visões hegemônicas, e sua integração ao modo de vida do colonizador era vista como inevitável, cumulada com o paulatino desaparecimento de suas particularidades culturais (como observou-se no tópico anterior). A criação do Serviço de Proteção aos Índios e Localização de Trabalhadores Nacionais (SPILTN) em 1910, antecessor da Fundação Nacional do Índio, por exemplo, teve o objetivo de afastar os indígenas "que constituíssem obstáculo ou estivessem à frente da fronteira econômica" (ARAUJO JR., 2018, p. 154), à medida que o Código Civil de 1916 e a Lei n. 5.484/1928 serviram à consolidação de um regime de tutela estatal para tratamento dos povos indígenas, regime esse que os separava da população nacional. Dessa forma, a tutela servia para controle sobre indivíduos considerados "potencialmente perigosos para a ordem estabelecida, uma vez que partilham [...] de condutas vistas como antissociais" (ARAUJO JR., 2018, p. 155).

No âmbito da Assembleia Constituinte de 1987/1988, persistiu o tratamento dos índios como potenciais adversários da soberania nacional e do desenvolvimento econômico, notadamente diante das reivindicações identitárias que se lograram incluídas no texto final da Constituição. Representantes das Forças Armadas e dos interesses de empresas mineradoras, apontavam os chamados perigos da demarcação de terras para a segurança das fronteiras e para o desenvolvimento da região amazônica, em discurso que reverbera no presente (ARAUJO JR., 2018, p. 184-185).

Em 1988, porém, a nova Constituição protagonizou, na esfera normativa nacional, a ruptura do paradigma assimilacionista presente nas relações entre povos indígenas e a sociedade hegemônica, bem como a quebra do regime de tutela estatal. Embora presente o respeito à posse indígena em âmbito constitucional desde 1934 sobre as terras em que se localizassem permanentemente, somente a atual Constituição valorizou a autonomia dos povos indígenas e o respeito a seus modos de vida, sem qualquer referência a uma perspectiva de integração.

\subsection{O delineamento constitucional do direito territorial no artigo 231 da CF/88: considerações sobre o direito originário, a propriedade da União e o usufruto exclusivo}

Os direitos originários dos índios sobre as terras tradicionalmente ocupadas eram objeto de discussão há muito. O Alvará de 10 de abril de 1680, no Brasil colonial, já apontava os indígenas como "primários e naturais senhores" sobre suas terras (SOUZA FILHO, 2006, p. 124), o que impulsionou a formulação da teoria do indigenato em 1912 por João Mendes Júnior. ${ }^{4}$ A Constituição de 1988 consolidou tal direito congênito e, segundo Araujo Jr. (2018), a potência do artigo 231 e seu viés transformador não vinculam necessariamente o reconhecimento do direito a um vínculo com o passado, ou seja, não se faz necessário, para atendimento a reivindicações identitárias, que o povo indígena possa ser ligado historicamente aos povos que ocupavam o território à época do achamento pelos europeus. Os processos de apropriação, territorialização, etnogênese e reivindicação desses povos são presentes, constantes, e são esses, sem necessária investigação de vínculos históricos específicos, também abarcados pela proteção constitucional (ARAUJO JR., 2018, p. 212).

A terra indígena foi juridicamente delineada na Constituição (BRASIL, 1988) como propriedade da União (artigo 20, XI), destinando-se aos índios a posse permanente e o usufruto exclusivo das riquezas do solo, dos rios e dos lagos nela existentes (artigo 231, §2ㅇ). Araujo enfatiza que a atribuição formal de propriedade à União deve ser interpretada de acordo com o novo paradigma constitucional de contorno pluralista, respeitoso à diversidade cultural e aberto ao diálogo intercultural, e, nesse sentido, serve a reforçar a proteção à propriedade indígena contra terceiros e viabilizar o exercício desse direito fundamental. O caput do artigo 231, em sua parte final, reforça tal conclusão ao estabelecer que compete à União demarcar as terras, proteger e

\footnotetext{
Segundo tal teoria, o título dos índios decorre do fato de serem índios, sem necessidade de legitimação.
} 
fazer respeitar todos os seus bens. Não se mostra compatível com o novo paradigma e com as previsões de usufruto exclusivo e posse permanente indígena, portanto, o reconhecimento à União dos poderes de usar, fruir e dispor da terra a seu favor, nos moldes clássicos do direito civil de propriedade (ARAUJO JR., 2018, p. 315-316). Para Souza Filho (2006, p. 123), o direito do Estado sobre a terra indígena sequer enquadra-se no conceito dogmático de propriedade ou bem público, por não se adequar às categorias de bens públicos dominicais, de uso especial ou de uso comum do povo, presentes no Código Civil.

A autonomia indígena no exercício de seu direito territorial, constitucionalmente reconhecida, portanto, impõe restrições à intervenção do Estado sobre territórios de ocupação tradicional. O papel da União é garantir o livre-desenvolvimento dos vínculos indígenas com o território, tanto sob a perspectiva do exercício dos poderes inerentes à posse e propriedade quanto sob a perspectiva espiritual, cultural, política e simbólica, presente em tais ligações (ARAUJO JR., 2018, p. 317).

Segundo Souza Filho (2006, p. 122), o termo "usufruto exclusivo", presente no caput do artigo 231, remete à intransferibilidade para apropriação individual, e significa que o resultado de qualquer uso, trabalho ou renda será sempre coletivo, da comunidade. Para Julio Araujo Jr. (2018), além do "usar" e "fruir", o usufruto exclusivo atende aos anseios indígenas quanto às formas próprias de lidar com o território, e garante "o exercício de direitos culturais, econômicos e sociais, abrangendo a reprodução social, cultural e espiritual da comunidade, o respeito à diversidade étnica, religiosa e cultural, a pluralidade socioambiental, econômica e cultural dessas comunidades" (p. 317). Aqui também o conceito distancia-se de sua clássica origem civilista, quando o usufrutuário, como detentor do direito real de fruir as utilidades e frutos de uma coisa, está subordinado aos poderes do proprietário, não podendo alterar a substância dessa coisa. Sobre o exercício do direito territorial indígena ao usufruto exclusivo, não deve haver ingerência da União (p. 318).

\subsection{O procedimento de demarcação de terras indígenas}

O processo administrativo de demarcação, de competência da União (artigo 231, caput), é atualmente regulamentado pelo Decreto n. 1.775/96, e se realiza por iniciativa e sob orientação do órgão federal de assistência ao índio (artigo 10 do decreto). Doutrina e jurisprudência concordam que, embora confira segurança formal ao reconhecimento, o direito indígena sobre o território não depende da conclusão do processo. Conquanto haja formulado uma série de interpretações limitativas do direito indígena no âmbito do julgamento do caso Raposa Serra do Sol (Pet. 3.388), o Supremo Tribunal Federal ressaltou, nessa oportunidade, que os direitos dos índios sobre as terras tradicionalmente ocupadas foram constitucionalmente "reconhecidos", não simplesmente outorgados, e, portanto, o ato de demarcação possui natureza declaratória, não constitutiva do direito. O ministro Ayres Britto, pautado na teoria do indigenato, destacou que o direito "originário" prepondera sobre pretensos direitos adquiridos, mesmo os materializados em escrituras públicas ou títulos de legitimação de posse em favor de não índios (a Constituição declarou esses atos "nulos e extintos" no § 60 do artigo 231). Prepondera, sobre a demarcação formal, a realidade e a efetiva ocupação tradicional. Nesse contexto, o conceito de terra indígena é subordinado aos usos, costumes e tradições do povo e, portanto, ao se demarcar uma terra indígena, faz-se necessário levar em consideração o sentimento do povo que a habita, para além da ideia moderna e hegemônica de patrimônio (SOUZA FILHO, 2006, p. 149).

Não obstante seu caráter meramente declaratório, o impedimento de demarcações é foco de interesses econômicos voltados à exploração de recursos e instalação de empreendimentos em áreas indígenas, e, diante da omissão governamental em acelerar os procedimentos demarcatórios, as áreas são focos de intensos conflitos entre índios e não índios.

Por outro lado, há processos de demarcação já concluídos, com decretos homologados, cuja delimitação de área não reflete, formalmente, a área de ocupação tradicional (terra indígena constitucional), por conta dos mencionados embates políticos e interesses subjacentes que permeiam o processo administrativo. A demarcação insuficiente impulsiona também conflitos, como é o caso da demarcação da área indígena Waimiri-Atroari, cujo decreto de homologação excluiu expressamente a área afetada à BR-174, apesar de ela atravessar o interior da terra indígena demarcada. Trata-se de forte indício de violação ao direito fundamental 
ao território tradicionalmente ocupado, e, no caso da área indígena Waimiri-Atroari, a revisão da demarcação, para excluir-se a exceção contida no parágrafo único do artigo 20 do decreto demarcatório, ${ }^{5}$ é objeto de ação civil pública em trâmite perante a 3 a ara da Justiça Federal do Amazonas. ${ }^{6}$

\section{A CONSULTA PRÉVIA COMO INSTRUMENTO DE RECONHECIMENTO DA AUTODETERMINAÇÃO DOS POVOS INDÍGENAS}

\subsection{Intervenção estatal e o direito à consulta prévia, livre e informada dos povos indígenas}

Não obstante o novo paradigma constitucional tenha ampliado e reforçado a proteção ao direito indígena sobre os territórios tradicionalmente ocupados, como fundamental que é, o direito de posse permanente e usufruto exclusivo não é absoluto, na medida em que outros valores com sede constitucional podem limitá-lo (MENDES, 2014). Nesse sentido, intervenções estatais poderão ocorrer se obedecidos os parâmetros de proporcionalidade e as normas constitucionais, infraconstitucionais e internacionais pertinentes. Toda intervenção poderá acarretar riscos à sobrevivência do grupo e sua proteção territorial cultural e constitucionalmente delineada, o que reforça o ônus argumentativo do Poder Público em sua pretensão de intervir com impacto nos territórios (ARAUJO JR., 2018, p. 318).

O tema perpassa a análise do direito à consulta prévia, livre e informada previsto na Convenção no 169 da Organização Internacional do Trabalho (OIT). Além da proteção constitucional, o direito indígena foi objeto de preocupação da seara internacional, e a comunidade internacional editou a Convenção no 169, tratado que marca, assim como a Constituição o fez em âmbito nacional, a ruptura do paradigma assimilacionista (em oposição à Convenção no 107/OIT, sua predecessora, que sustentava perspectivas de integração do índio à sociedade hegemônica).

A Convenção no 169/OIT entrou em vigor, em âmbito internacional, em 5 de setembro de 1991, e foi ratificada pelo Brasil em 2002, entrando no ordenamento jurídico nacional por meio do Decreto Presidencial n. 5.051, de 19 de abril de 2004 (WAGNER, 2014, p. 09-10). Em se falando de tratado internacional de direitos humanos, essa norma, segundo o Supremo Tribunal Federal, possui hierarquia normativa supralegal (Recurso Extraordinário n. 466.343, julgado em 3 de dezembro de 2008); ${ }^{7}$ portanto toda lei infraconstitucional deve guardar conformidade com suas disposições. Ademais, seus direitos possuem aplicabilidade imediata nos termos do artigo 5o, § 1으, da Constituição, independentemente de regulamentação.

Almeida (2008, p. 49-52) afirma que o texto da Convenção baseia-se na autodefinição dos agentes sociais, ${ }^{8}$ reconhece a usurpação de terras desde o domínio colonial e os casos de expulsão e deslocamento compulsório, além de contemplar tanto regiões de colonização antiga quanto situações sociais referentes a regiões de ocupação recente.

Sobressaem para a presente pesquisa os dispositivos da Convenção concernentes à consulta prévia, livre e informada dos povos indígenas. ${ }^{9}$ Estabelece o artigo 60 da Convenção que os governos deverão consultar os povos interessados por meio de procedimentos adequados e, em particular, de suas instituições representativas, sempre que sejam previstas medidas legislativas ou administrativas suscetíveis de afetá-los diretamente. A norma estabelece ainda que as consultas deverão ser conduzidas de boa-fé e de maneira adequada às circunstâncias, no sentido de que possa ser alcançado um acordo ou consentimento em torno das medidas propostas.

\footnotetext{
Decreto n. 97.837/1989. Artigo $2^{\circ}$ [...]. Parágrafo único. Ficam excluídas, da área descrita, a superfície de inundação da barragem da Usina Hidrelétrica de Balbina, conforme Decreto n 85.898, de 13 de abril de 1981, e a faixa de domínio da BR174.

6 Processo n. 1001605-06.2017.401.3200.

7 Flavia Piovesan defende o status constitucional dos tratados internacionais sobre direitos humanos, com fundamento no artigo 5으, $§ 2$, da Constituição, cumulado com o § 3ㅇ do mesmo artigo (2009, p. 5).

8 Juliana Santilli destaca esse aspecto ao afirmar que "a Convenção no 169, da Organização Internacional do Trabalho (OIT), sobre Povos indígenas e tribais, estabelece que o critério fundamental para determinar os grupos (indígenas e tribais) a que se aplicam as suas disposições deve ser a consciência de sua identidade indígena ou tribal (ou seja, a própria auto-identificação)" (2005, p. 91).

9 Para Maria Luiza Grabner, "a observância do princípio da consulta e do consentimento livre, prévio e informado é, a nosso sentir, a maior garantia existente hoje, no plano jurídico, de realização de um diálogo intercultural entre os povos indígenas e outras comunidades tradicionais com outros segmentos das sociedades nacionais e internacional, e de que depende, em grande parte, a legitimidade e efetividade da proteção jurídica que Ihes é conferida pelos Estados" (2015, p. 14).
} 


\section{Direito自

Para Deborah Duprat (2015), a consulta tem por pressuposto o domínio dos povos sobre sua existência, deve ser prévia ("sempre que sejam previstas"), bem-informada ("conduzidas de boa-fé"), culturalmente situada ("adequada às circunstâncias") e tendente a chegar a um consentimento sobre a medida proposta. Pressupõe-se, assim, que o projeto ainda não tenha sido decidido, que as posições possam ser revistas por meio de diálogo prévio por influência desse direito, pois "aquilo que se apresenta como já decidido não enseja, logicamente, consulta, pela sua impossibilidade de gerar qualquer reflexo na decisão" (p. 68).

Ademais, com a adequação da consulta às circunstâncias culturais, chega-se à conclusão de que não há modelo único de consulta; ela se desenvolve de acordo com as peculiaridades de cada grupo. Alguns grupos reservam as decisões aos caciques, outros aos anciãos, professores, à totalidade do grupo ou a instâncias representativas.

Quanto ao povo Waimiri-Atroari, a que se refere esta pesquisa, em seu protocolo de consulta disponibilizado na internet, dispôs sobre a forma que devem assumir as consultas prévias a ele direcionadas. No documento, o povo exige respeito, clareza e transparência sobre toda e qualquer questão que venha a afetá-los, de modo que possa entender os possíveis impactos positivos e negativos das decisões do Poder Público sobre a terra, as pessoas, a identidade, a floresta e os animais. Exige-se, ainda, a presença de intérprete e tradutor, das lideranças indígenas e de representantes da Funai, e registros em áudio e vídeo feitos pelos próprios indígenas. Em suma, as discussões iniciais, internas à comunidade, deverão chegar a um consenso, que será apresentado ao governo em reunião geral (ATROARI, 2018, p. 19-23).

Não há como subverter esse processo mediante uma solução externa, e cabe à intermediação antropológica aproximar os interlocutores e possibilitar de fato o diálogo (DUPRAT, 2015, p. 70-71).

No que diz respeito aos efeitos da consulta, Duprat (2015) critica as posições extremas que ou consideram a consulta uma mera formalidade, ou vislumbram a possibilidade incondicional de veto ao projeto que se visa a executar em área indígena. Uma vez reconhecidos os direitos indígenas nacional e internacionalmente, numa sociedade plural, "nenhum grupo pode ter o domínio absoluto das decisões que escapam ao seu exclusivo interesse" (p. 72). A autora cita como exemplo de aplicação desse direito pela Corte Interamericana de Direitos Humanos, o caso Saramaka vs. Suriname, em cujo julgamento se fez distinção entre consulta e consentimento. Exigir-se-á este último nas hipóteses de grandes projetos de empreendimento que provoquem perda de território ou seu grave comprometimento no que diz respeito ao acesso, uso e gozo dos recursos fundamentais à existência física e cultural do grupo.

\subsection{Considerações sobre o novo constitucionalismo latino-americano e a transição para um paradigma jurídico pluralista}

O entendimento suprarreferido, aplicado ao caso Saramaka vs. Suriname pela CIDH, é consequência direta da virada paradigmática no âmbito do direito: a propriedade privada, em sua relação com o indivíduo e seu viés de apropriação econômica, era a única homologada pelo direito, até que passou a conviver com a propriedade como locus étnico e cultural, de coletividades, territórios e espaços de pertencimento (DUPRAT, 2015, p. 72-73).

A alteração na forma de encarar o clássico conceito de propriedade privada é um dos sintomas de uma mudança mais abrangente: a de paradigma jurídico, a qual se tem constatado em países latino-americanos de capitalismo periférico que adotaram, modernamente, padrões eurocêntricos de ordenamento jurídico e organização social.

O autor Antônio Carlos Wolkmer (2001, p. 237), ao dispor sobre essa transição, parte da constatação de que a racionalidade de ordem burguesa, formalista e individualista, que ascendeu entre os séculos 17 e 18 com autores iluministas e culminou nos modelos modernos de Estado nacional e soberano, não mais atende às demandas sociais em sociedades marcadas por conflitos entre grupos e classes. $O$ autor destaca o papel dos sujeitos coletivos na modernidade e discorre sobre o modelo pluralista do direito, pautado numa racionalidade emancipatória. Ao manifestarem-se como novos movimentos sociais, dotados de identidade e autonomia, esses sujeitos coletivos têm assumido o papel de protagonistas na edificação da cidadania e criação do direito. Uma postura ativa, de efetivo protagonismo, tem elevado os movimentos sociais à condição de emancipados, participantes e criadores de sua própria história, e dentre eles encontram-se os povos indígenas. 
Para Modernell e Oliveira (2018), é forçoso perceber a emergência do novo constitucionalismo latino-americano, que empreende enorme esforço para romper com a hegemonia da cultura ocidental em relação à cultura dos povos indígenas. Segundo esse constitucionalismo de transição, os Estados estão avançando em direção a uma etapa pluricultural, na qual ganha relevo o pluralismo jurídico, que consiste no reconhecimento, pelo Estado, de um direito paralelo ao direito positivado pelo próprio Estado, caracterizando a diversidade de direito no mesmo ordenamento jurídico (normas jurídicas positivadas e normas jurídicas não estatais).

O pluralismo jurídico está fundado na diversidade do Estado, que passa a reconhecer os diversos povos que o compõem, promovendo a interculturalidade. Nesse sistema, as minorias étnicas, como os povos indígenas, ganham expressão e maior participação no Estado democrático, pois, com esteio no tratamento igualitário dispensado aos povos, estes passam a influir cada vez mais nas instituições estatais em razão do exercício do poder que lhes são outorgados. Com maior influência nas instituições do Estado, os povos indígenas podem ver seus anseios albergados pelas políticas estatais.

Nesse viés, é possível entrever que, numa sociedade plural, a força normativa da constituição é retirada dos diversos povos integrantes do Estado, privilegiando diversas culturas pertencentes a um mesmo território e permitindo a construção de uma cidadania justa.

Nessa nova interpretação atribuída às constituições latino-americanas, que poderá fomentar estudos concernentes à hermenêutica constitucional brasileira (guardadas as devidas proporções, o que deve ser objeto de novos estudos), os povos indígenas conquistam maior visibilidade social, de modo que cumpre ao Estado observar suas idiossincrasias na formulação das políticas públicas, na elaboração das leis e na prestação jurisdicional.

Nesta oportunidade, convém consignar que a consulta prévia aos povos impactados por projetos estatais emerge como um instrumento a permitir que esses povos possam influir nas decisões do Estado que integram, mormente como corolário da horizontalização da constituição, perspectiva segundo a qual o Estado passa a interpretar a constituição de forma a respeitar os direitos dos povos tradicionais, em contraposição à verticalização da constituição, em que há predominância da cultura ocidental hegemônica.

Quanto ao ordenamento jurídico brasileiro, Cavalcante (2018) relata o anacronismo da regulamentação dos direitos dos povos indígenas. Para a articulista, ainda são necessárias mudanças que possibilitem a superação hermenêutica do paradigma integracionista, abandonando a ideia de assimilação dos índios pela cultura prevalente entre os não índios.

\subsection{A consulta prévia como instrumento de reconhecimento}

A ideia defendida neste artigo circunda em torno da necessidade de utilização do instituto da consulta prévia aos indígenas Waimiri-Atroari, como mecanismo de efetivação dos seus direitos ante as tentativas de retirada, pelo Poder Público, do bloqueio por eles efetuado na BR-174, dentro da área tradicionalmente ocupada na região amazônica.

Conforme dispõe Machado (2017) em sua obra sobre o princípio jurídico da fraternidade, a Constituição de 1988 trouxe, em seu preâmbulo, o ideal de uma sociedade plural. Em sua tese, a autora defende a efetividade do princípio da fraternidade no ordenamento jurídico como instrumento de proteção dos direitos transindividuais. Para tanto, entende que a fraternidade é expressão da própria dignidade humana, pois, quando o homem reconhece a existência de sua dignidade, passa a compreender não somente a sua, mas também a dignidade do outro. Surge, então, em decorrência da fraternidade, o reconhecimento da existência do outro e o dever de responsabilidade quando da violação de seus direitos.

Acerca da influência da fraternidade na democracia, a referida autora propugna ainda que a vontade da maioria não tem o condão de suprimir as minorias, ao revés, os direitos destas devem ser assegurados por aquelas para que Ihes possibilite ser maioria um dia. Vislumbra-se, portanto, que a democracia não dá azo para a discriminação de minorias étnicas, como os povos indígenas, cabendo à sociedade buscar meios de preservar os direitos e a identidade desses povos perante a cultura ocidental hegemônica.

É justamente nesse contexto que Brígida e Bentes (2019) expressam que em cada cultura existe um ideal de dignidade. Não se pode, assim, traduzir a dignidade sempre na visão dos direitos humanos internacionais, pois cada cultura interpreta e transmite sua concepção de dignidade. 
As autoras tecem comentários ao multiculturalismo, raiz do pluralismo político de cunho liberal, assegurado na Constituição de 1988 por meio da dignidade da pessoa humana, pois seria o homem digno por ser racional e por ter autonomia da vontade. Segundo as autoras, tais conceitos reforçam a autodeterminação dos povos, haja vista que o respeito à dignidade possibilita a convivência de culturas diferentes, sem que uma tente sobrepujar a outra. Quanto a este último ponto, elucidam que se faz necessária a presença do Estado, por meio de políticas afirmativas, na inclusão de minorias vulneráveis.

Como se pode perceber, a pluralidade conduz o Estado e os indivíduos a reconhecerem a existência do outro, bem como a imprescindibilidade do respeito mútuo, em razão da dignidade humana. Nessa vereda, resta evidente como é premente a proteção dos povos indígenas como minoria étnica no Estado brasileiro por respeito à dignidade dos seus indivíduos. Ademais, a sua participação nas decisões sociais é reflexo do regime democrático, que apregoa a máxima e efetiva participação popular na vida do Estado.

\subsection{A consulta prévia como instrumento de autodeterminação}

Outro documento internacional - a Declaração das Nações Unidas sobre os Povos Indígenas -, embora não formalmente vinculante, consolida o entendimento dos Estados sobre a matéria e conforma normas e interpretações (ARAUJO JR., 2018, p. 253). Em seu artigo 3, consolida o direito à livre-determinação, não mencionado expressamente pela Convenção n. 169/OIT. ${ }^{10}$ Segundo o documento, os indígenas determinam livremente sua condição política e perseguem, também livremente, seu desenvolvimento econômico, social e cultural. No exercício desse direito, possuem autonomia e autogoverno nas questões relacionadas com seus assuntos internos e locais.

Ao discorrer sobre a autodeterminação, Caroline Nogueira (2016) liga o exercício desse direito à resistência e à liberdade de manifestação da vontade coletiva dos povos indígenas, ao decidirem sobre sua forma de organização política, social e jurídica, e sobre suas relações entre si e com a natureza, com base em sua própria cultura e tradições. Decorrente da ordem jurídica nacional e internacional, o direito à autodeterminação distancia-se da pretensão de se desvincular e constituir novo Estado soberano (direito de secessão), e se perfectibiliza na autonomia para decidir sobre ações que interfiram direta ou indiretamente em seu território, o que descarta a superioridade estatal e seu poder absoluto para definir os rumos de uma nação plural sob moldes exclusivamente eurocentristas (p. 116-117).

No mesmo sentido, Araujo Junior (2018) esclarece que na Declaração da Organização das Nações Unidas - ONU - é assegurado aos povos indígenas o direito à autodeterminação. Frisa, porém, que tal direito não se traduz no desmembramento, total ou parcial, da unidade política estatal. Ao contrário, a autodeterminação tem o objetivo de assegurar e promover as estruturas institucionais desses povos, os costumes, as tradições, os procedimentos, as práticas e os sistemas jurídicos próprios, em conformidade com as normas internacionais de direitos humanos.

Ao trazer o debate para o âmbito da interpretação constitucional realizada pelo Supremo Tribunal Federal, o autor entende que o tribunal, no julgamento da Petição 3.388 (caso Raposa Serra do Sol), equivocou-se ao compreender a Declaração da ONU como instrumento emancipacionista das comunidades indígenas e, mais ainda, ao deixar de aplicar o regulamento supralegal constante da Convenção no 169 da OIT em consonância com as normas constitucionais. O jurista explica que, apesar de o STF não ter negado a validade da consulta prévia prevista na Convenção, ressalvou que aquela não é requisito de validade para a decisão administrativa tampouco vincula o Poder Público.

\footnotetext{
${ }^{10}$ A Convenção, porém, em seu artigo 7ำ, dispõe que "Os povos interessados deverão ter o direito de escolher suas próprias prioridades no que diz respeito ao processo de desenvolvimento, na medida em que ele afete as suas vidas, crenças, instituições e bem-estar espiritual, bem como as terras que ocupam ou utilizam de alguma forma, e de controlar, na medida do possível, o seu próprio desenvolvimento econômico, social e cultural. Além disso, esses povos deverão participar da formulação, aplicação e avaliação dos planos e programas de desenvolvimento nacional e regional suscetíveis de afetá-los diretamente."
} 
Neste ponto, Araújo Junior (2018) sustenta a necessidade de diálogo das normas internas com as internacionais, bem como com as decisões proferidas pelas Cortes de outros países, numa visão cosmopolita sobre o assunto, apregoando que é substancial um diálogo verdadeiro dos Estados com os povos indígenas, mediante instrumentos como o de consulta, a fim de salvaguardar o real consentimento dos povos impactados, embora a Convenção não preveja necessariamente um direito de veto.

Desse modo, não se pode conceber a realização de consultas aos povos indígenas como procedimentos meramente formais. A consulta é um mecanismo positivado na legislação com o objetivo de assegurar a efetiva participação desses povos no processo decisório do governo estatal. A consulta prévia, livre e informada, consiste numa verdadeira garantia de defesa e proteção dos povos tradicionais.

No mesmo sentido, é o posicionamento defendido pelo Ministério Público Federal na ação civil pública no 1001605-06.2017.4.01.3200 (BRASIL, 2017, p. 122, num. 2518053), conforme excerto a seguir transcrito:

A consulta não deve ser realizada da maneira como entende o Estado ou o empreendedor privado. Não pode ser um instrumento meramente homologatório de uma decisão previamente tomada. Para ser considerada válida, a consulta aos povos indígenas afetados deve ser formal e realizada de boa-fé, de maneira prévia, livre e informada. No que tange ao caráter prévio da consulta, depreende-se que esta deve ser anterior a qualquer intervenção sobre a área eventualmente afetada, ou seja, a consulta deve ocorrer no momento em que a decisão está prestes a ser tomada.

Minorias étnicas são comumente postas à margem do poder exercido na sociedade, entretanto um Estado constituído com o propósito de tutelar interesses dos seus cidadãos, não pode segregar uns e privilegiar outros, sob o risco de negar os componentes de sua própria existência.

Não só se constata, portanto, a importância da consulta prévia aos povos indígenas no que se refere à interlocução com o Poder Público, mas também a sua aplicação de modo que observe o consentimento externado por tais povos, a fim de que tenham, efetivamente, tutelados seus interesses pelo Estado que integram.

\section{CONCLUSÃO}

A falta de diálogo entre os governos brasileiros e os povos indígenas é histórica. Um dos casos mais emblemáticos diz respeito à construção da BR-174 durante o regime militar, que provocou um verdadeiro genocídio do povo indígena Waimiri-Atroari, decorrente do pensamento assimilacionista adotado à época, que buscava persuadir os povos indígenas a aderirem aos empreendimento estatais.

Hoje em dia, ainda como reflexo da intervenção forçada no território indígena do povo Waimiri-Atroari para a construção da BR-174, emerge o conflito a respeito do bloqueio intermitente da rodovia pelos índios. Assim, diferentemente do ocorrido no passado, vislumbra-se, como mecanismo de solução do conflito, o emprego da consulta prévia aos Waimiri-Atroari pelo Estado de Roraima, a fim de possibilitar um diálogo concreto com os indígenas, garantir sua efetiva participação na decisão do ente estatal e manter uma convivência pacífica entre as sociedades indígenas e não indígenas na região.

A consulta prévia, livre e informada consiste em um dos principais institutos jurídicos compreendidos no ordenamento jurídico interno e internacional, que garantem a participação dos povos indígenas na defesa de seus direitos ante as interferências estatais. Encontra-se consignada no artigo 6o da Convenção no 169 da Organização Internacional do Trabalho como instrumento apto a oportunizar uma efetiva atuação desses povos na discussão de políticas públicas, mormente quanto às decisões governamentais que implicam medidas que interferem, direta ou indiretamente, em sua vivência nas comunidades.

Com efeito, trata-se de um importante mecanismo democrático para os povos indígenas que ainda enfrentam dificuldades tanto para garantir proteção às terras que tradicionalmente ocupam quanto para resguardar seus demais direitos atinentes à sua identidade, cultura, língua, crenças, tradições, terras, costumes, modos de vida e outros atributos que lhe são ínsitos.

A leniência na atualização do arcabouço jurídico brasileiro revela a fragilidade na proteção dos direitos dos povos indígenas. Dessa forma, com suporte, principalmente, na legislação internacional de vanguarda sobre os direitos dos povos indígenas, compreende-se a consulta prévia como instrumento necessário e 
obrigatório para a defesa e a proteção de seus direitos, diante da intervenção do Estado brasileiro nas terras indígenas, sob o discurso desenvolvimentista de levar progresso a espaços territoriais distantes dos centros urbanos do país.

É importante salientar que, além de constituir um mecanismo de limitação do discurso desenvolvimentista, o instituto da consulta prévia reafirma a superação do discurso social assimilacionista ainda ressonante acerca da integração dos povos indígenas à sociedade dita "civilizada", bem como fortalece o reconhecimento da autodeterminação desses povos.

Por fim, depreende-se que a inserção e a compatibilidade do instituto da consulta prévia com o direito doméstico, sobretudo em relação às normas da Constituição de 1988, convergem para uma proteção mais efetiva dos direitos dos povos indígenas e, consequentemente, para a construção de uma sociedade plural.

\section{REFERÊNCIAS}

ALMEIDA, A. W. B. D. Terra de quilombo, terras indígenas, "babaçuais livre", "castanhais do povo", faxinais e fundos de pasto: terras tradicionalmente ocupadas. 2. ed. Manaus: PGSCA-Ufam, 2008.

ARAUJO JUNIOR, J. J. Direitos territoriais indígenas: uma interpretação intercultural. Rio de Janeiro: Processo, 2018.

ATROARI, A. C. W. Protocolo de consulta ao povo Waimiri-Atroari. 2018. Disponível em: https://www.socioambiental.org/sites/blog.socioambiental.org/files/nsa/arquivos/protocolo_waimiri_atroari_2018.pdf\#overlay-context=pt-br/noticias-socioambientais/conhecimento-agricola-quilombola-fica-mais-perto-de-virar-patrimonio-imaterial-brasileiro. Acesso em: out. 2019.

BARRETO FILHO, H. T. Populações tradicionais: introdução à crítica da ecologia política de uma noção. In: ADAMS, C.; MURRIETA, R.; NEVES, W. (org.). Sociedades caboclas amazônicas: modernidade e invisibilidade. São Paulo: Fapesp; Annablume, 2006. p. 109-143.

BRASIL. Constituição da República Federativa do Brasil, de 5 de outubro de 1988. Disponível em: http://www.planalto.gov.br/ ccivil_03/constituicao/constituicaocompilado.htm. Acesso em: out. 2019.

BRASIL. Decreto no 1.775 (Procedimento administrativo de demarcação), de 8 de janeiro de 1996. Disponível em: http://www. planalto.gov.br/ccivil_03/decreto/d1775.htm. Acesso em: out. 2019.

BRASIL. Decreto no 5.051 (Convenção no 169 da OIT), de 19 de abril de 2004. Disponível em: http://www.planalto.gov.br/ccivil_03/_ato2004-2006/2004/decreto/d5051.htm. Acesso em: out. 2019.

BRASIL. Decreto no 97.837 (homologa a demarcação administrativa da Área Indígena WAIMIRI-ATROARI), de 16 de junho de 1989. Disponível em: http://www.planalto.gov.br/ccivil_03/decreto/1980-1989/D97837.htm. Acesso em: out. 2019.

BRASIL. Justiça Federal Seção Judiciária do Amazonas. Ação Civil Pública no 1001605-06.2017.4.01.3200. Autor: Ministério Público Federal. Réus: União e Fundação Nacional do Índio. Juíza Federal: Raffaela Cássia de Souza. Manaus, 18 de agosto de 2017. Disponível em: https://pje1g.trf1.jus.br/pje-web/login.seam. Acesso em: out. 2019.

BRASIL. Lei no 6.001 (Estatuto do Índio), de 19 de dezembro de 1973. Disponível em: http://www.planalto.gov.br/ccivil_03/ Leis/L6001.htm. Acesso em: out. 2019.

BRASIL. Ministério Público do Estado do Paraná: Legislação Geral sobre Comunidades Tradicionais. Disponível em: http://www. direito.mppr.mp.br/modules/conteudo/conteudo.php?conteudo=62. Acesso em: set. 2019.

BRÍGIDA, Y. S. S.; BENTES, N. S. A sacralidade da pessoa num mundo multicultural. Revista Bonijuris, Curitiba, v. 31, n. 2, ed. 657, p. 120-136, abr./maio 2019.

CALEGARE, M. G. A.; HIGUCHI, M. I. G.; BRUNO, A. C. dos S. Povos e comunidades tradicionais: das áreas protegidas à visibilidade política de grupos sociais portadores de identidade étnica e coletiva. Ambiente \& Sociedade, São Paulo, v. XVII. p. 115-134, 2014.

CARNEIRO DA CUNHA, M.; ALMEIDA, M. W. B. Populações tradicionais e conservação ambiental. In: CAPOBIANCO, J. (org.). Biodiversidade amazônica. Avaliação e ações prioritárias para a conservação, uso sustentável e repartição de benefícios. São Paulo: Estação Liberdade; Instituto Socioambiental, 2001.

CAVALCANTE, T. M. M. A. Multiculturalismo no Brasil: uma análise da evolução na defesa da identidade dos povos indígenas. Revista Jurídica da Seção Judiciária de Pernambuco, Recife, n. 11, p. 359-374, 2018.

DUPRAT, D. (org.). Convenção n. 169 da OIT e os Estados Nacionais. Brasília: ESMPU, 2015.

FUNAI. Entenda o processo de demarcação. Disponível em: http://www.funai.gov.br/index.php/2014-02-07-13-24-53. Acesso em: out. 2019

GRABNER, M. L. O direito humano ao consentimento livre, prévio e informado como baluarte do sistema jurídico de proteção dos conhecimentos tradicionais. Boletim Científico ESMPU, Brasília, a. 14, n. 45, p. 11-65, jul./dez. 2015. 
INSTITUTO SOCIOAMBIENTAL. Declaração das Nações Unidas Sobre os Direitos dos Povos Indígenas. Disponível em: https:// pib.socioambiental.org/files/file/PIB_institucional/DECLARACAO_DAS_NACOES_UNIDAS_SOBRE_OS_DIREITOS_DOS_POVOS_ INDiGENAS.pdf. Acesso em: out. $201 \overline{9}$.

MACHADO, C. O Princípio Jurídico da Fraternidade: um instrumento para proteção de direitos fundamentais transindividuais. Rio de Janeiro: Lumen Juris, 2017.

MENDES, G. F.; BRANCO, P. G. G. Curso de direito constitucional. São Paulo: Saraiva, 2014.

MODERNELL, B. D. L.; OLIVEIRA, D. M. O novo constitucionalismo latino-americano e os desafios para uma sociedade plural e jusdiversa. In: SILVEIRA, E. D. da; CAMARGO, S. A. F. de (coord.). Socioambientalismo de fronteiras: direito indígena e ambiental. Curitiba: Juruá, 2018. V. 6.

MOURA, M. V. L. Terra indígena Waimiri-Atroari e a BR-174: direitos constitucionais em conflito na Amazônia brasileira à luz da técnica de ponderação. 2017. Monografia (Graduação em Direito) - Universidade Federal de Roraima, 2017. Disponível em: http://ufrr.br/direito/index.php?option=com_phocadownload\&view=category\&download=324:terra-indigena-waimiri-atroari-e-a-br-174-direitos-constitucionais-em-conflito-na-amazonia-brasileira-a-luz-da-tecnica-de-ponderacao-autora-mariana-von-linde-moura-orientador-prof-dr-isaias-montanari-junior\&id=66:monografia-2017-2\&ltemid=314. Acesso em: out. 2019.

MPF. Ministério Público Federal. 2018. Ação Civil Pública c/c pedido de tutela provisória de urgência em face de Estado do Pará - Secretaria Estadual de Meio Ambiente e Sustentabilidade do Pará. Disponível em: http://www.mpf.mp.br/pa/sala-de-imprensa/documentos/2018/acao_mpf_suspensao_licenciamento_complexo_hidreletrico_rio_cupari_pa_consulta_previa_livre_informada.pdf. Acesso em: out. 2019.

NOGUEIRA, C. B. C. A autodeterminação dos povos indígenas frente ao Estado. Curitiba: Pontifícia Universidade Católica do Paraná, 2016.

OLIVEIRA, A. D. C. Direitos e/ou povos e comunidades tradicionais: noções de classificação em disputa. Desenvolvimento $e$ Meio Ambiente, Paraná: Editora UFPR, v. 27, p. 71-85, 2013.

ONU. Organização das Nações Unidas. Assembleia geral. Declaração das Nações Unidas sobre os Direitos dos Povos Indígenas, de 13 de setembro de 2007. Disponível em: https://www.un.org/esa/socdev/unpfii/documents/DRIPS_pt.pdf. Acesso em: out. 2019.

PIOVESAN, Flavia. Parecer da dra. Flavia Piovesan do dia 23 de março de 2009. Disponível em: www.mpf.mp.br/atuacao-tematica/ccr6/dados-da-atuacao/grupos-de-trabalho/gt-quilombos/legislacao-1/adi3239/parecer-dra-flavia-piovesan-do-dia-23-de-marco-de-2009. Acesso em: out. 2019.

SANTILLI, J. Socioambientalismo e novos direitos: proteção jurídica à diversidade biológica e cultural. 2005. Disponível em: http://portal.iphan.gov.br/uploads/ckfinder/arquivos/SANTILLI_Juliana-Socioambientalismo-e-novos-direitos.pdf.

SOUZA FILHO, C. F. M. de. O renascer dos povos indígenas para o direito. 1. ed. Curitiba: Juruá, 2006.

STF. Supremo Tribunal Federal. A Constituição e o Supremo. Item 241 de 378. Disponível em: http://www.stf.jus.br/portal/ constituicao/artigobd.asp?item=\%202051. Acesso em: out. 2019.

WAGNER, D. F. Dez anos após a entrada em vigor da Convenção 169 da OIT no Brasil: um olhar sob a perspectiva da efetividade. 2014. Disponível em: http://www.publicadireito.com.br/artigos/?cod=acf73df8e44ed30b.

WOLKMER, A. C. Pluralismo jurídico: fundamentos de uma nova cultura no Direito. 3. ed. São Paulo: Editora Alfa Omega, 2001. 